\title{
Promoting Pragmatic Competence in Teaching English as a Foreign Language
}

\author{
Xiaoyang Shu \\ Teaching Center, Zhejiang Radio \& TV University, Hangzhou, China \\ Email: sxy327love@126.com
}

How to cite this paper: Shu, X.Y. (2018) Promoting Pragmatic Competence in Teaching English as a Foreign Language. Open Access Library Journal, 5: e4398. https://doi.org/10.4236/oalib.1104398

Received: February 2, 2018

Accepted: April 23, 2018

Published: April 26, 2018

Copyright (๑) 2018 by author and Open Access Library Inc.

This work is licensed under the Creative Commons Attribution International License (CC BY 4.0).

http://creativecommons.org/licenses/by/4.0/

\section{(c) (i) Open Access}

\begin{abstract}
Pragmatic competence is an indispensable element of communicative competence. Whoever wants to communicate successfully in a foreign language wants to promote their communicative competence, as well as their pragmatic competence. This paper begins with clarifying the definition of pragmatic competence by referring to other linguists' explanations. Then it discusses the importance of promoting language learners' pragmatic competence in communication, and tries to explore the necessity and feasibility of teaching pragmatic competence in FL teaching process. Finally, the paper proposes some tentative approaches to promote pragmatic competence in teaching English as a foreign language.
\end{abstract}

\section{Subject Areas}

Education

\section{Keywords}

English Teaching, Pragmatic Competence, Communicative Competence, Pragmatic Failure

\section{Introduction}

"Pragmatics is concerned with the study of meaning as communicated by a speaker (or writer) and interpreted by a listener (or reader)" [1]. Since the Journal of Pragmatics was first published in 1977 in Holland, pragmatics has drawn more and more attention from both linguists and educators. People realize that pragmatics, different from other sub-disciplines of linguistics which tell how to understand and use language, tells more about how to use language appropriately.

Today, with the development of social economy and world environment, FL 
learners are not just content with linguistic knowledge, such as vocabulary and grammar rules. Instead, they are eager to promote their language competence, most important, pragmatic competence, so that they can use the language in communication. Therefore, a number of linguists and those who are interested in pragmatics begin to put pragmatic theories into practice; for example, they begin to make research to find how to promote language learners' pragmatic competence.

\section{Definition of Pragmatic Competence}

Language learning is a process of promoting pragmatic competence. Different scholars hold different opinions on the definition of pragmatic competence. $\mathrm{He}$ Ziran introduced some of them in Pragmatics and English Learning [2].

Hymes (1972) first expanded the concept of competence proposed by Norm Chomsky in 1960s, and then put forward that term of communicative competence, which consists of four components: possibility, feasibility, appropriateness and performance. It is generally believed that the first component is equal to linguistic competence, while the rest three components are submitted to pragmatic competence.

Leech (1983) first distinguished pragmalinguistics and sociopragmatics, thus pragmatic competence is divided into two parts of pragmalinguistic competence and sociopragmatic competence. The former is a pragmatic competence of using correct grammar and appropriate language form to realize certain communication, while the latter requires the speaker to conform to the social rules of language use to reach proper communication.

Besides, Bachman in 1990 provided a much more detailed illustration about linguistic competence (see Table 1).

In his illustration, as for the two parts of pragmatic competence, illocutionary competence refers to the competence of understanding communicative act and knowing how to carry it out; and socio-cultural competence refers to the competence of using language appropriately in specific context.

To sum up, pragmatic competence is the competence of understanding and using language correctly and appropriately in a particular context to achieve successful communication.

\section{The Importance of Promoting Pragmatic Competence}

The purpose of learning a foreign language is to use it in communication, that is

Table 1. Bachman's illustration of linguistic competence.

\begin{tabular}{|c|c|c|c|}
\hline \multicolumn{4}{|c|}{ Language competence } \\
\hline \multicolumn{2}{|c|}{ Organization competence } & \multicolumn{2}{|c|}{ Pragmatic competence } \\
\hline $\begin{array}{l}\text { Grammatical } \\
\text { competence }\end{array}$ & Discourse competence & $\begin{array}{l}\text { Illocutionary } \\
\text { competence }\end{array}$ & $\begin{array}{c}\text { Socio-cultural } \\
\text { competence }\end{array}$ \\
\hline
\end{tabular}


to say, learning English is to cultivate English learners' communicative competence. Since pragmatic competence is an essential element of communicative competence; it should be important in learning English.

\subsection{The Relationship between Language Form and Language Function}

Traditionally, teachers mainly teach language form and grammatical rules, but neglect the language function and language use. Many teachers believed that with the study of language form and grammatical rules, FL learners would gradually realize the language function and acquire the competence to use the language. However, recent research findings show that pragmatic competence could not develop spontaneously with grammatical competence [3]. In other words, there exists a great gap between language form and language function or language use.

Theoretically, if language form always coincides with language function, the communication will be direct and easy to understand. But the actual relationship between language form and language function is hierarchical. Due to various contexts, a single language form may entail various language functions, and a single language function may be transmitted in different language forms. For example, "The door is open." at least has the following functions in different situation:

1) Stating or explaining the fact "the door is open";

2) Reminding the hearer of closing the door when he or she leaves;

3) Scolding the hearer of not having closed the door;

4) Suggesting that it is cold in the room and requesting the hearer to close the door.

On the other hand, to realize the language function of requesting the hearer to close the door, the speaker has various choices:

1) Door!

2) Close the door, please.

3) Would you please close the door?

4) Do you mind closing the door?

5) It's cold in here.

This simple example serves to illustrate that language form is different from language function. And to achieve successful communication needs to know the hierarchical relationship between language form and language function and to use appropriate language form, which involves advanced pragmatic competence.

\subsection{The Relationship between Grammatical Rules and the Rules of Language Use}

When people use their native language to communicate with each other, they conform to both the formal rules of language, that is, grammatical rules, and the functional rules of language, that is, rules of language use. But concerning with the FL learners, they may violate either of the rules or even both of them. This 
suggests an important point in learning foreign languages, that is, we should know both grammatical rules and rules of language use and apply them in the practice.

What deserves our notice is that some grammatically correct sentences are hardly acceptable in pragmatic principles; and some sentences, although ungrammatical, are valuable in certain context.

a) (A Chinese principle introduced an American teacher to the staff and all the students) Ladies and gentlemen, I'm delighted to introduce to you a very pretty girl, Miss Brown. She is a very good teacher from the USA...

b) I can't do it very good.

(He 1997: 202-203)

In sentence a), the school principle utters grammatically correct sentence, but it will make the American teacher embarrassed and uncomfortable. First, "girl" is a term for innocent and immature females in western culture, so a female over 18 would prefer to be called "woman" or "lady", and second, western people tend to objectively introduce the guests, without any partial evaluation. Contrarily, sentence b) is ungrammatical but still acceptable in certain context.

This example tells that in real communication, appropriate use of language in particular context is much more important than grammatical correctness. It also shows the importance of pragmatic competence in communication.

\subsection{Pragmatic Failure}

"Pragmatic failure does not refer to the performance errors in language use, in making phrases and sentences. Instead, it is caused by the inappropriateness of speech, either the improper way of speaking or unidiomatic language expressions, which make it impossible to achieve the desired effect." [4]. Thomas [5] said in Cross-cultural Pragmatic Failure that in speech communication, if the speaker could not make phrases and sentences according to the standard grammatical encoding scheme, he would at most be considered "speaking badly", but if he/she does not obey the pragmatic principles in speaking, he would probably be regarded as "behaving badly", or as insincere, deceitful, and dishonest person. Here, we can recognize that pragmatic failure would do great harm to interpersonal communication, so we must do our best to overcome it.

However, it is not an easy job to overcome pragmatic failure. Just concerning the use of "please", Ron White [6] has discovered several situations in which pragmalinguistic failure occurs. Take one situation as an example, $\mathrm{H}$ and $\mathrm{S}$ have just finished a meeting in an unfamiliar part of the building, and $\mathrm{H}$ is leaving while $S$ is returning to her office. They come to an elevator which is located in a different part of the building from the one normally taken by $\mathrm{H}$ :

$\mathrm{H}$ to $\mathrm{S}$ : I can take this elevator, can I?

$\mathrm{S}$ to H: Yes. Please get off on the ground floor.

By the misuse of "please", $S$ turned her confirmation into a request and violated Grice's quantity maxim by giving more information than is needed. $\mathrm{H}$ 
might get confused when hearing such a reply, so S actually made the situation an instance of pragmalinguistic failure.

Ron White concluded the situations of pragmalinguistic failure as the following: 1) conflicting signals; 2) creating tension; 3) risking offence; 4) creating confusion; 5) public embarrassment; 6) interpersonal breakdown. Only a "please" could have so many kinds of pragmatic failure, and cause a lot of problems in communication. So we should pay more attention to pragmatic competence so as to diminish pragmatic failure in communication.

\section{The Necessity and Feasibility of Teaching Pragmatic Competence}

After discussing the importance of promoting pragmatic competence, some other questions come to our minds: can pragmatic competence be developed naturally with the enlargement of vocabulary and the command of grammatical knowledge, or is it necessary to teach pragmatic competence? And can pragmatic competence be taught?

Because of the universality of some pragmatic knowledge, FL learners may induce from their native language some principles in organizing the speech; they may express their intention indirectly; or they may make use of context to understand indirect meanings, etc. However, educational psychologists have found that foreign language learners are not capable to transfer all the useful knowledge and strategies to foreign language studies. They are more likely to comprehend the speech or discourse literally rather than freely making inference with the help of context.

Another reason why pragmatic competence should be taught in English studies is that pragmatic competence cannot develop spontaneously with the development of vocabulary and grammar. Honggang examined the pragmatic failure of two groups of English majors by a questionnaire, one group freshmen, and the other seniors. The result shows that freshmen are apparently inferior to seniors in linguistic competence, but they are similar in pragmatic competence (see Table 2).

Although at average, the seniors have a better command of linguistic knowledge, they do not possess a corresponding better pragmatic competence. This investigation, though carried out in one university, reflects the universal problem existed in our college English education. And it also proves that pragmatic competence cannot develop spontaneously with linguistic competence, and affirms the necessity of teaching pragmatic competence.

Table 2. A comparison of pragmatic failure between freshmen and seniors.

\begin{tabular}{ccc}
\hline & Freshmen & Seniors \\
\hline Mean failure & $47.76 \%$ & $46.6 \%$ \\
Pragmalinguistic failure & $52.5 \%$ & $52.85 \%$ \\
Sociopragmatic failure & $32.96 \%$ & $42.39 \%$ \\
\hline
\end{tabular}


As for the feasibility of teaching pragmatic competence, great efforts have been made in an attempt to promote foreign language learners' pragmatic competence in language teaching. Research findings show that teaching pragmatic competence should initiate from enhancing the pragmatic awareness, then embody more pragmatic knowledge in everyday language teaching, and create as much opportunity as possible for language learners to use the pragmatic knowledge in the communication.

\section{Some Tentative Approaches of Promoting Pragmatic Competence in Teaching English as a Foreign Language}

Having understood the importance of promoting pragmatic competence and the possibility of teaching pragmatic competence in the process of English teaching, the author in this part attempts to provide some tentative approaches to promote pragmatic competence in teaching English as a foreign language.

\subsection{Enhancing the Pragmatic Awareness}

Promoting pragmatic competence should initiate from enhancing the pragmatic awareness, both of FL learners' awareness and teachers' awareness. Bardovi-Harlig [7] has argued that pragmatic awareness should be one goal of classroom instruction. Only if both language learners and teachers have realize the importance of pragmatic competence and be active in promoting their pragmatic competence, could they make some improvements in the English teaching and learning process, and could their pragmatic as well as communicative competence be promoted.

\subsection{Promoting Pragmatic Competence in the Practice}

Firstly, we should distinguish language form and language function in English learning and teaching. Teachers should not be content with only teaching large quantities of vocabulary and grammar to the students; instead, they should design some situations to provide opportunities for the students to use the language knowledge. And students should catch every possible chance to use what they have learnt, either linguistic or pragmatic knowledge, into practice.

Secondly, in teaching English, teachers should focus on context. Whatever he/she teaches, he/she should take context into consideration. In the previous discussion, we have seen that one same sentence may have different meanings and functions in different contexts. Teachers should help students understand the significant role that context plays in the language use.

Thirdly, teachers should cultivate students' sensitivity towards the culture divergence in English teaching. People with different culture background would have different understandings even for the same word. "People have similar meanings only to the extent that they have had or can anticipate similar experiences." [8]. Without the accurate understanding of the culture of target language, FL learners would misunderstand or misuse the foreign language. For 
example, an American host or hostess, when complimented on his or her cooking, is likely to respond, "Oh, I'm so glad you liked it. I cooked it especially for you." In contrast, the Chinese host or hostess will apologize for not giving you delicious or even edible food and for not showing you enough honor. Such culture difference can never be understood through the mere study of linguistic knowledge. So it is teachers' responsibility to cultivate students' sensitivity towards the culture divergence in English teaching, which will help the students to promote their pragmatic competence.

\section{Conclusions}

This paper is devoted to discussing the hot issue of promoting FL learners' pragmatic competence. From the definition of pragmatic competence, the author includes pragmatic competence as a crucial part of communicative competence, which is the essential objective of learning a foreign language. Then the paper discussed the importance of promoting pragmatic competence, the necessity and feasibility of teaching pragmatic competence in FL teaching process. Finally, it put forward some tentative approaches to help language teachers and students to promote their pragmatic competence.

Therefore, the paper has called people's attention to this issue, and may help the language learners to promote their pragmatic competence.

\section{Acknowledgements}

My thanks to the anonymous reviewers for reading and commenting on the early drafts of this article.

\section{Funding}

The project is supported by the Program for Research on Educational Technology of China (Grant No. 146241759), 312 Personnel Training Project of Zhejiang Open University, the Foundation of Distance Education: Development and Innovation (Grant No. 2014ZX02), Social Science Project of Hangzhou in 2017 (Grant No. M17JC021), High-quality Course Project-Essentials of Translation.

\section{References}

[1] Yule, G. (2000) Pragmatics. Shanghai Foreign Language Education Press, Shanghai, 3.

[2] He, Z.R. (1997) Pragmatics and English Learning. Shanghai Foreign Language Education Press, Shanghai, 199-201.

[3] Hong, G. (1991) A Survey of English Pragmatic Competence and Enlightenment of Foreign Language Teaching. Foreign Language Teaching and Research, 4, 56-60.

[4] He, Z.R. (1997) Pragmatics and English Learning. Shanghai Foreign Language Education Press, Shanghai, 205-206.

[5] Thomas, J. (1983) Cross-Cultural Pragmatic Failure. Applied Linguistics, 4, 91-112. https://doi.org/10.1093/applin/4.2.91

[6] White, R. (1993) Saying Please: Pragmalinguistic Failure in English Interaction. ELT 
Journal, 47, 193-202. https://doi.org/10.1093/elt/47.3.193

[7] Bardovi-Harlig, K. and Dörnyei, Z. (1998) Do Language Learners Recognize Pragmatic Violations? Pragmatic versus Grammatical Awareness in Instructed L2 Learning. TESOL Quarterly, 32, 233-262. https://doi.org/10.2307/3587583

[8] Samovar, L.A., et al. (2000) Communication between Cultures. 3rd Edition, Foreign Language Teaching and Research Press, Beijing, 124-129. 